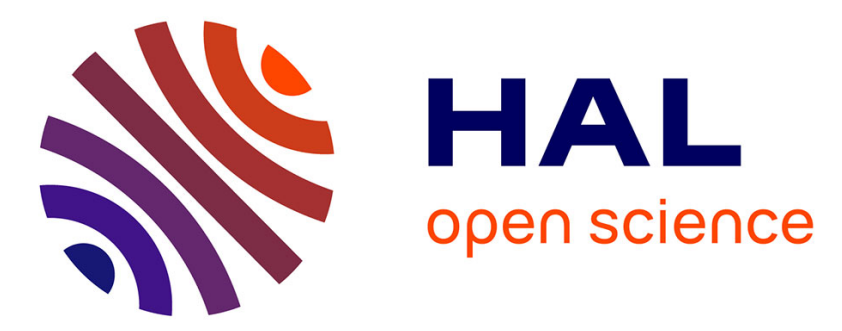

\title{
Tailoring the interaction between graphene oxide and antibacterial pyridinium salts by terminal functional groups
}

R. Fujii, K. Okubo, S. Takashiba, A. Bianco, Y. Nishina

\section{- To cite this version:}

R. Fujii, K. Okubo, S. Takashiba, A. Bianco, Y. Nishina. Tailoring the interaction between graphene oxide and antibacterial pyridinium salts by terminal functional groups. Carbon, 2020, 160, pp.204-210. 10.1016/j.carbon.2019.11.094 . hal-02994626

\section{HAL Id: hal-02994626 \\ https://hal.science/hal-02994626}

Submitted on 12 Nov 2020

HAL is a multi-disciplinary open access archive for the deposit and dissemination of scientific research documents, whether they are published or not. The documents may come from teaching and research institutions in France or abroad, or from public or private research centers.
L'archive ouverte pluridisciplinaire HAL, est destinée au dépôt et à la diffusion de documents scientifiques de niveau recherche, publiés ou non, émanant des établissements d'enseignement et de recherche français ou étrangers, des laboratoires publics ou privés. 


\title{
Tailoring the Interaction between Graphene Oxide and Antibacterial Pyridinium Salts by Terminal Functional Groups
}

\author{
R. Fujii, ${ }^{1}$ K. Okubo, ${ }^{2}$ S. Takashiba, ${ }^{2}$ A. Bianco, ${ }^{3}$ Y. Nishina ${ }^{1,4 *}$
}

${ }^{1}$ Graduate School of Natural Science and Technology, Okayama University, Okayama, Japan

${ }^{2}$ Graduate School of Medicine, Dentistry and Pharmaceutical Sciences, Okayama University,

Okayama, Japan

${ }^{3}$ CNRS, Immunology, Immunopathology and Therapeutic Chemistry, University of Strasbourg, ISIS, Strasbourg, France

${ }^{4}$ Research Core for Interdisciplinary Sciences, Okayama University, Okayama Japan

*Corresponding Author’s Email: nisina-y@cc.okayama-u.ac.jp (YN) 
Abstract

Nanocarbons, especially two-dimensional carbons, have received considerable attention due to their unique structure and physical and chemical properties, which make them promising candidate materials for biomedical applications. In this study, we focus on graphene oxide (GO), which has many oxygenated functional groups and high affinity with water and biomaterials, and the synthesis of GO complexes with antibacterial agents, like cetylpyridinium chloride (CPC) and its derivatives. We found that the sustained release of CPCs from GO can be controlled by changing the terminal functional group of CPC. The prepared GO-CPC complexes were subjected to antibacterial tests against S. mutans. $\mathrm{CPC}$ with the carboxy group was degraded by the oxidizing property of $\mathrm{GO}$, resulting in the loss of antibacterial properties. On the other hand, the other $\mathrm{CPC}$ derivatives were released from GO and showed antibacterial activities. Finally, we propose a new mechanism describing how GO and CPC form a functional complex, and how CPC is released from this complex. These findings will lead to pioneering the carbon-based functional antibacterial agents designed at the molecular level. 


\section{Introduction}

Microorganisms exist in all environments, such as air, soil, and water, and they adsorb to the surface of substances to form complex cell communities called biofilms. ${ }^{1}$ Once the biofilm is formed, the inner bacteria are protected from antibiotics and difficult to remove mechanically, becoming tough to kill and eliminate. For this reason, it is highly demanding to develop a material that can control the adhesion of microorganisms on the surface endowed of antibacterial activities. So far, antibacterial substances, such as silver nanoparticles, ${ }^{2}$ hydrophilic substances like heparin and hyaluronic acid, ${ }^{3}$ polymers that prevent adhesion of bacteria by steric hindrance, ${ }^{4}$ and enzymes that cleave biofilm matrices, ${ }^{5}$ have been studied as surface coating materials. However, these coatings are immobilized weakly on the surface by physical adsorption, thus presenting the problem of low durability. A sustained and controlled drug release system helps in the maintenance of a drug concentration and retards the release rate of the drug, thereby extending the duration of the action. To control the release of antibacterial agents, we focused on tailoring the interaction between a support material and an antibacterial reagent by changing the terminal functional group of the reagent. ${ }^{6}$

Nanocarbons are chemically stable and have a high specific surface area, and thus considered as promising long-lasting hosts or carriers for antibacterial agents. In particular, 2-dimensional (2D) carbons, such as graphene, are suitable to cover a surface uniformly and to exert sufficient antibacterial properties even when used in small amounts. ${ }^{7} 2 \mathrm{D}$ carbons can enhance their functions by controlling their structure at the atomic level. Graphene oxide (GO), which is an oxidized form of graphene, has different functional groups (e.g., hydroxyl, carboxyl, carbonyl, and epoxy groups ) and small graphitic domains. $^{8}$ GO can immobilize molecules by covalent bonding, ionic interactions, hydrogen interactions, and physisorption. ${ }^{9}$ However, there are no guidelines describing how the binding mode 
between GO and the molecules affects the antibacterial activity and persistence. Therefore, we decided to evaluate the binding mode and the amount of the introduced and leached molecules by changing the functional group (e.g. carboxyl, hydroxyl, amino, and pyrenyl groups) of a class of antibacterial molecules. To this end, we selected cetylpyridinium chloride (CPC) as a model compound because it bears a functionalizable long alkyl chain and an antibacterial quarternary nitrogen atom. CPC exhibits a broad spectrum of antibacterial properties against gram-positive bacteria, gram-negative bacteria, and some common pathogenic fungi and flagellates at concentrations below showing toxicity to human cells. ${ }^{10}$ Similarly to molecules containing quaternary ammonium cations, CPC acts on lipid bilayers, creating hydrophilic gaps that cause cytoplasm to flow out leading to cell death. ${ }^{11} \mathrm{CPC}$ is widely used in oral care products but has several disadvantages, such as fast elimination. ${ }^{12}$ Therefore, we synthesized CPC derivatives possessing a functional group at the terminal position of the alkyl chain that would not interfere with the active site responsible for the antibacterial properties (e.g., quaternary nitrogen). The CPCs were complexed with GO, then evaluated for the release from GO and their antibacterial activities. The present study provides a guideline for the molecular design of antibacterial agents with fine control of release profile and antibacterial activity.

\section{Experimental}

\subsection{Synthesis of CPC derivatives}

\subsubsection{CPC with a carboxyl group (СРС Соон)}

16-Hexadecanolide $(1 \mathrm{~g}, 3.93 \mathrm{mmol})$ and tetrabutylammonium hydrogen sulfate $\left(18.7 \mathrm{mg}, 5.3 \times 10^{-2}\right.$ mmol) were mixed in toluene $(5 \mathrm{~mL})$, then $50 \%$ aq. $\mathrm{NaOH}(3.33 \mathrm{~mL})$ was added. The mixture was stirred at $90{ }^{\circ} \mathrm{C}$ overnight. After cooling, the formed crystals were filtered and washed with diethyl 
ether. The collected crystals were dispersed in water, and the $\mathrm{pH}$ was adjusted to 1.5 by adding $1 \mathrm{M}$ aq. $\mathrm{HCl}$. The crystals were again filtered, washed with water, and dried under vacuum to obtain 16hydroxydecanoic acid (1) in $82 \%$ yield.

Compound 1 (100 mg, $0.37 \mathrm{mmol})$ was dissolved in DMF $(0.5 \mathrm{~mL})$, and $\mathrm{SOCl}_{2}(0.5 \mathrm{~mL}$, excess $)$ was added at $0{ }^{\circ} \mathrm{C}$. Then, the mixture was heated up to $65^{\circ} \mathrm{C}$ and stirred for $3 \mathrm{~h}$ at the same temperature. After cooling, excess $\mathrm{SOCl}_{2}$ was removed in vacuo until the total volume was reduced to ca. $0.2 \mathrm{~mL}$. The mixture was cooled to $0{ }^{\circ} \mathrm{C}$, added water, and stirred at room temperature for $1 \mathrm{~h}$, extracted by AcOEt, purified by column chromatography (AcOEt: hexane=1: 8) to obtain 16-chlorohexadecanoic acid (2) in $91 \%$ yield.

Compound $2(100 \mathrm{mg}, 0.35 \mathrm{mmol})$ was dissolved in pyridine $(2 \mathrm{~mL})$ and heated at $100{ }^{\circ} \mathrm{C}$ overnight. After cooling, the formed crystals were collected by filtration, washed with hexane, and dried under vacuum to obtain CPCсоон. Yield: $88 \%$.

\subsection{2 СРC with a hydroxyl group (СРСон)}

Compound 2 (290.6 mg, $1.0 \mathrm{mmol})$ was dissolved in dehydrated diethyl ether $(5 \mathrm{~mL})$, and $2 \mathrm{M} \mathrm{LiAlH}_{4}$ dispersed in THF $(0.75 \mathrm{~mL}, 1.5 \mathrm{mmol})$ was added at $0{ }^{\circ} \mathrm{C}$. The mixture was stirred at room temperature for $2 \mathrm{~h}$, then quenched stepwise under vigorous stirring with water $(58.5 \mu \mathrm{L}), 15 \%$ aq. $\mathrm{NaOH}(58.5$ $\mu \mathrm{L})$, and water $(175.5 \mu \mathrm{L})$. After $1 \mathrm{~h}$, the mixture was filtered through Celite and dried in vacuo to obtain 16-chlorohexadecanol (3) in 81\% yield.

Compound 3 (100 mg, $0.36 \mathrm{mmol})$ was dissolved in pyridine $(2 \mathrm{~mL})$ and heated at $100{ }^{\circ} \mathrm{C}$ overnight. After cooling, the formed crystals were collected by filtration, washed with hexane, and dried under vacuum to obtain СРСон. Yield: 53\%.

\subsubsection{CPC with an amino group $\left(\boldsymbol{C P}_{\mathrm{NH}}\right)$}


Compound 1 (100 mg, $0.37 \mathrm{mmol})$ was dissolved in DMF $(0.5 \mathrm{~mL})$, and $\mathrm{SOCl}_{2}(0.5 \mathrm{~mL}$, excess) was added at $0{ }^{\circ} \mathrm{C}$. Then, the mixture was heated up to $65^{\circ} \mathrm{C}$ and stirred for $3 \mathrm{~h}$ at the same temperature. After cooling, excess $\mathrm{SOCl}_{2}$ was removed in vacuo until the total volume was reduced to ca. $0.5 \mathrm{~mL}$. The mixture was cooled to $0{ }^{\circ} \mathrm{C}$, was added $28 \%$ aq. $\mathrm{NH}_{4} \mathrm{OH}$ and stirred at room temperature for $1 \mathrm{~h}$, extracted by AcOEt, purified by column chromatography (AcOEt: hexane =1: 8) to obtain 16chlorohexadecanamide (4) in 44\% yield.

Compound 4 (100 mg, $0.34 \mathrm{mmol})$ was dissolved in dehydrated diethyl ether $(5 \mathrm{~mL})$, and $2 \mathrm{M} \mathrm{LiAlH}_{4}$ dispersed in THF $(0.75 \mathrm{~mL}, 1.5 \mathrm{mmol})$ was added at $0{ }^{\circ} \mathrm{C}$. The mixture was stirred at room temperature for $2 \mathrm{~h}$, then quenched stepwise under vigorous stirring with water $(19.5 \mu \mathrm{L}), 15 \%$ aq. $\mathrm{NaOH}(19.5$ $\mu \mathrm{L})$, and water $(58.5 \mu \mathrm{L})$. After $1 \mathrm{~h}$, the mixture was filtered through Celite and dried in vacuo to obtain 1-chloro-16-hexadecanamine (5) in 87\% yield.

Compound 5 (100 mg, $0.36 \mathrm{mmol})$ was dissolved in pyridine $(2 \mathrm{~mL})$ and heated at $100{ }^{\circ} \mathrm{C}$ overnight. After cooling, the formed crystals were collected by filtration, washed with hexane, and dried under vacuum to obtain $\mathbf{C P C} \mathbf{N H}_{2}$. Yield: $51 \%$.

\subsubsection{CPC with a pyrenyl group $\left(\boldsymbol{C P}_{\boldsymbol{p y}}\right)$}

Compound $3(1.20 \mathrm{~g}, 3.55 \mathrm{mmol})$ in dichloromethane $(10 \mathrm{~mL})$ at $0{ }^{\circ} \mathrm{C}$ was added tetrabromomethane ( $1.40 \mathrm{~g}, 4.26 \mathrm{mmol})$ followed by triphenylphosphine $(1.40 \mathrm{~g}, 5.33 \mathrm{mmol})$, added portionwise over 10 minutes. The reaction mixture was stirred for $1 \mathrm{~h}$, concentrated under vacuum, and then diethyl ether was added. The resultant solids were removed by filtration, and the filtrate was concentrated under vacuum to obtain 1-bromo-16-chlorohexadecane (6) in 99\% yield.

Pyrene (4.05 g, $20 \mathrm{mmol})$ was dissolved in $16 \mathrm{~mL}$ acetic acid and $60 \mathrm{~mL}$ benzene. The mixture was stirred at room temperature until pyrene was completely dissolved. The round-bottom flask was then 
fitted with a reflux condenser and purged with Ar. Lead (IV) acetate (9.83 g, $22.2 \mathrm{mmol}$ ) was added to the flask. The reaction mixture was then refluxed for $3 \mathrm{~h}$. The reaction mixture was allowed to cool to room temperature, dried under vacuum, extracted with chloroform, and purified by column chromatography (toluene: hexane= $15: 85$ ) to obtain 1-acetoxy pyrene in $27 \%$ yield.

1-Acetoxy pyrene $(2.14 \mathrm{~g}, 9.84 \mathrm{mmol})$ was dissolved in $20 \mathrm{~mL}$ of ethanol and $10 \mathrm{~mL}$ of water. The round-bottom flask was equipped with a reflux condenser. To this was added $2.13 \mathrm{~g}$ (53.3 mmol) of $\mathrm{NaOH}$. The mixture was heated under Ar at $75{ }^{\circ} \mathrm{C}$ for $3 \mathrm{~h}$. The resulting solution was allowed to cool to room temperature. The ethanol was concentrated under vacuum until the total volume was reduced to ca. $10 \mathrm{~mL}$, then the solution was transferred to an ice bath. Concentrated $\mathrm{HCl}(37 \%)$ was then added dropwise. The $\mathrm{pH}$ was adjusted to 1 . The resulting suspension was filtered and washed with water. The powder was dried in vacuo, and 1-hydroxyl pyrene (7) was obtained in 95\% yield.

Compound 7 (74.9 mg, $0.34 \mathrm{mmol})$ and potassium carbonate $(113.7 \mathrm{mg}, 1.65 \mathrm{mmol})$ were added in a mixed solvent of $3 \mathrm{~mL} \mathrm{DMF}$ and $3 \mathrm{~mL}$ THF. After compound 7 was dissolved into the solution, compound 6 (140 mg, $0.41 \mathrm{mmol})$ was added. The reaction mixture was stirred overnight under Ar at $65^{\circ} \mathrm{C}$. After cooling to room temperature, the reaction mixture was added $5 \mathrm{~mL}$ water, and the resulting suspension was then added to $50 \mathrm{~mL}$ of water. The solid was separated by filtration and dried in vacuo at $50{ }^{\circ} \mathrm{C}$ for $2 \mathrm{~h}$. The resulting solid was purified by column chromatography (AcOEt: hexanes $=15$ : 85) to obtain 1-(16-hexadecyloxy)pyrene (9) in 69\% yield.

Compound $9(100 \mathrm{mg})$ was dissolved in pyridine $(2 \mathrm{~mL})$, and heated at $100{ }^{\circ} \mathrm{C}$ overnight. After cooling, the formed crystals were collected by filtration, washed with hexane, and dried under vacuum to obtain

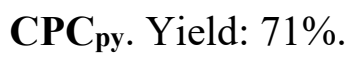




\subsection{Preparation of $G O$}

GO was prepared following the previously developed method in our group. ${ }^{13}$ In brief, natural flake graphite $(3.0 \mathrm{~g})$ was stirred in $95 \% \mathrm{H}_{2} \mathrm{SO}_{4}(75 \mathrm{~mL}) . \mathrm{KMnO}_{4}(9.0 \mathrm{~g})$ was gradually added to the solution keeping the temperature $<10{ }^{\circ} \mathrm{C}$. The mixture was then stirred at $35^{\circ} \mathrm{C}$ for $2 \mathrm{~h}$. The resulting mixture was diluted by water $(75 \mathrm{~mL})$ under vigorous stirring and cooling so that temperature does not exceed $50{ }^{\circ} \mathrm{C}$. The suspension was further treated with $30 \%$ aq. $\mathrm{H}_{2} \mathrm{O}_{2}(7.5 \mathrm{~mL})$. The resulting GO suspension was purified by centrifugation with water, then dialyzed until $\mathrm{pH}$ became $>5$.

\subsection{Surface functionalization of GO with CPCs}

Twenty $\mathrm{mL}$ of an $8.4 \mathrm{mg} / \mathrm{mL} \mathrm{GO}$ dispersion in water and $1.0 \mathrm{mg} / \mathrm{mL} \mathrm{CPCs} \mathrm{(added} \mathrm{amount} \mathrm{are} \mathrm{reported}$ in Table 1) were mixed under vigorous stirring, dispersed gently by bath-type sonicator for $30 \mathrm{~min}$, and freeze-dried. SEM images of the GO-CPCs are shown in Figure S1.

\subsection{Evaluation of release of CPCs from $G O$}

Two and a half $\mathrm{mg}$ of GO-CPC complex in $2.0 \mathrm{~mL}$ of water was vigorously stirred. Small portions of the mixture were taken up after $0.5,1,3,5,9$, and $25 \mathrm{~h}$, then centrifuged and filtered with PTFE membrane filter (pore size: $200 \mathrm{~nm}$ ). UV-Vis measurement was performed for the supernatant solutions, and the concentration of CPCs was determined using a calibration curves of pure CPCs (Figure S2).

\subsection{Evaluation of the antibacterial activity of $G O-C P C s$}

\subsubsection{Preparation of test solutions}

Each substance (GO, CPCs, or GO-CPCs) was dissolved or dispersed in phosphate-buffered saline 
(PBS: Gibco, USA, pH 7.4) at the concentrations of $5 \times 10^{-2}(\mathrm{w} / \mathrm{v})$ in bacterial solutions.

\subsubsection{Bacteria}

Streptococcus mutans (S. mutans) ATCC 25175 strain (ATCC, USA) was aerobically cultured in brain heart infusion (BHI: Becton, Dickinson and Company, Sparks, MD, USA) liquid media at $37{ }^{\circ} \mathrm{C}$ for 6 h (i.e., logarithmic growth phase). S. mutans was diluted to $10^{5} \mathrm{cfu} / \mathrm{mL}$ using BHI liquid media. We measured the turbidity of bacteria solution by the photometer (Miniphoto 518R: Taitec, Saitama, Japan; wavelength $660 \mathrm{~nm}$ ) for each test solution.

\subsubsection{Measurement of the amount of adenosine triphosphate $(A T P)^{14}$}

The amount of ATP present in the bacteria was used to test their viability. After bacteria were subjected to the test solutions for $12 \mathrm{~h}$, the ATP amount was measured using a Lucifer HS kit and Lumi-tester C110 (Kikkoman Bio-Chemiphar, Tokyo, Japan), which employs luciferin-luciferase reaction. The amount of luminescence was recorded as the values of the relative light unit (RLU, detection range: $1.0 \times 10^{-16}$ to $3.0 \times 10^{-11}$ moles of ATP). Background ATP present outside the bacterial cells was removed using adenosine phosphate deaminase. Statistical processing was performed using Student's t-test after using an F-test to analyze the variance between groups. P-values ( $p$ ) less than 0.01 as compared to all negative controls were considered statistically significant.

\section{Results and discussion}

\subsection{Conjugation of CPCs to GO}

GO contains various types of oxygenated functional groups (hydrophilic moiety) and non-oxidized graphene-like domains (hydrophobic areas). Furthermore, GO has an overall negative charge on its surface. $^{15,16}$ Therefore, the interaction of GO and CPCs varies depending on the functional groups on 
CPC. ${ }^{17}$ The maximum amounts of CPC and its derivatives adsorbed onto GO were determined by measuring the UV-Vis spectra of the supernatant solutions of the mixtures after sonication for $1 \mathrm{~h}$ and centrifugation (Table 1). Comparing the CPC derivatives containing a carboxyl group (СРСсоон), hydroxyl group (СРСон), amino group $\left(\mathbf{C P C}_{\mathbf{N H}}\right)$, and pyrenyl group $\left(\mathbf{C P C}_{\mathbf{P y}}\right)$, we found that pristine CPC showed the highest complexation efficiency. $\mathbf{C P C}_{\mathbf{p y}}$ was insoluble in water due to the high hydrophobicity of the pyrene moiety. Therefore, the amount of adsorbed $\mathbf{C P C}_{\mathbf{p y}}$ onto GO would be lower than the value determined by this method. Actually, smaller amount of nitrogen was observed

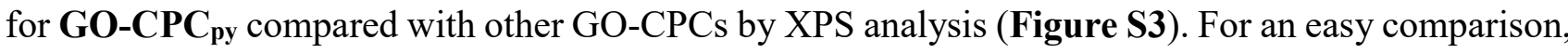
the amount of CPCs onto GO was adjusted to $0.25 \mathrm{mg} / \mathrm{mg}$ of GO in the following antibacterial tests.

Table 1. The maximum amount of CPCs used in the complexation with GO.

\begin{tabular}{|c|c|c|c|c|c|}
\hline CPC derivatives & $\mathrm{CPC}$ & $\mathrm{CPC}_{\mathrm{COOH}}$ & $\mathrm{CPC}$ & $\mathrm{CPC}_{\mathrm{NH} 2}$ & $\mathrm{CPC}_{\mathrm{py}}$ \\
\hline $\begin{array}{l}\text { Maximum amount }{ }^{a} \\
(\mathrm{mg} / \mathrm{mg} \text { of } \mathrm{GO})\end{array}$ & 0.45 & 0.40 & 0.25 & 0.30 & $(0.30)^{b}$ \\
\hline
\end{tabular}

${ }^{a}$ The weight ratio of $\mathrm{CPCs} / \mathrm{GO}$ in which $>95 \%$ of CPCs were adsorbed on GO.

${ }^{\mathrm{b}} \mathbf{C P C} \mathbf{C}_{\mathbf{p y}}$ was not completely soluble in water; therefore, this value is considered to be overestimated.

\subsection{Structural analysis of GO-CPC complexes}

To confirm the successful complexation of $\mathrm{CPC}, \mathbf{C P C} \mathbf{C O O H}, \mathbf{C P C o H}$, and $\mathbf{C P C}_{\mathbf{N H} 2}$ onto GO, we measured Fourier-transformed infrared (FT-IR) spectra of the different complexes (Figure 1). GO has peaks at $1630 \mathrm{~cm}^{-1}(\mathrm{C}=\mathrm{C}), 1730 \mathrm{~cm}^{-1}(\mathrm{C}=\mathrm{O})$, and a large band at 2500-3600 $\mathrm{cm}^{-1}(\mathrm{OH})$ (Figure 1i). GO-CPC showed peaks at 2700-3000 $\mathrm{cm}^{-1}$, suggesting the successful introduction of the alkyl chain (Figure 1ii). The other complexes of GO and CPCs showed FT-IR spectra similar to GO-CPC. An increased $\mathrm{C}=\mathrm{O}$ band was observed at $1700-1750 \mathrm{~cm}^{-1}$ for GO-CPCСоOH (Figure 1iii), while the other functional groups derived from CPC derivatives were not detected due to the low amount of CPCs 
adsorbed onto GO surface (Figure 1iv and 1v).

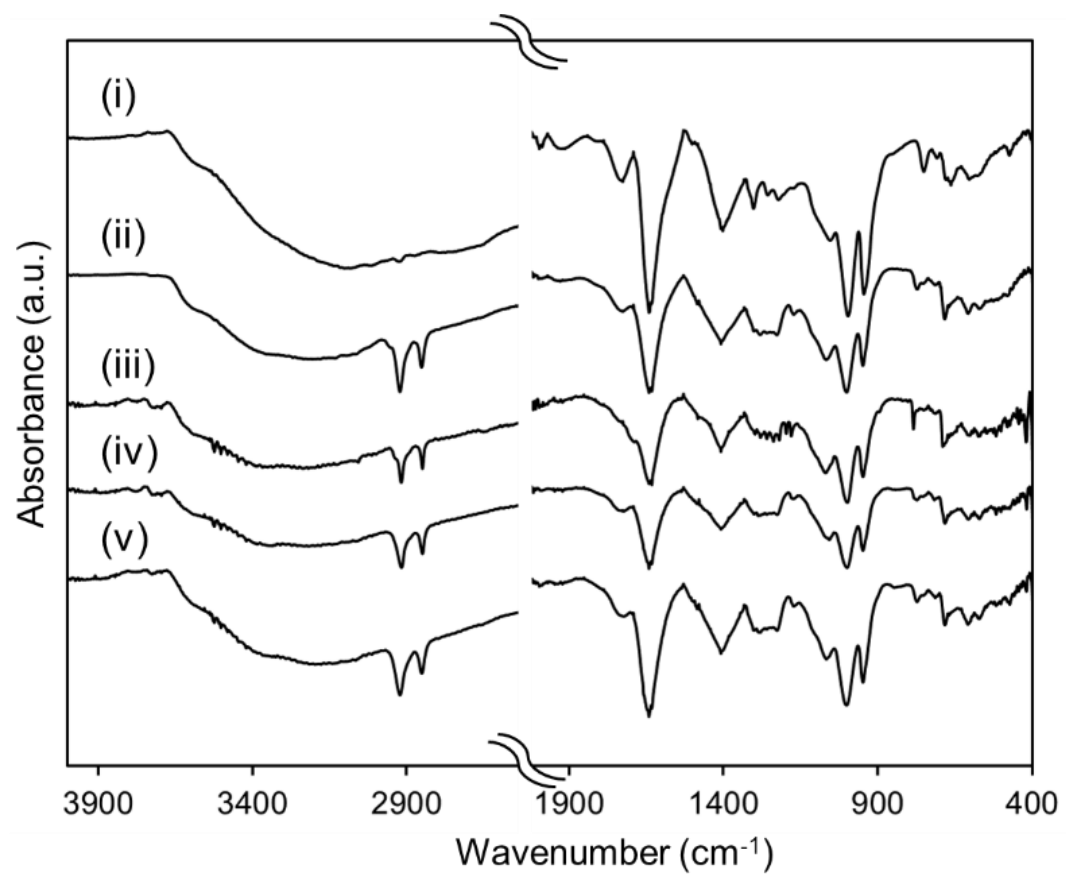

Figure 1. FT-IR spectra of (i) GO, (ii) GO-CPC, (iii) GO-CPC $\mathbf{C O O H}$, (iv) GO-CPCoH, and (v) GO$\mathrm{CPC}_{\mathrm{NH}}$.

Next, we measured X-ray diffraction (XRD) patterns to confirm the uniform functionalization of GO with CPCs. CPC has XRD signals at $2 \theta=18.9,15.8,12.6$, and $6.4^{\circ}$ (Figure 2i). XRD patterns of GO alone had a (002) diffraction peak at $2 \theta=11.3^{\circ}$ (Figure 2ii). GO-CPC complexes showed different patterns form CPC-like signals, suggesting uniform distribution of CPCs onto GO sheets without the formation of CPC particles (Figure 2iii-6vi). This result is opposite to a previous report, in which the XRD pattern of CPC was observed, ${ }^{16}$ likely because we carefully optimized the amount of CPCs, as shown in Table 1. Moreover, GO-CPC complexes showed no GO pattern, suggesting random complexation derived from the ionic interactions between the negatively charged $\mathrm{GO}$ and $\mathrm{CPC}$ quaternary nitrogens. ${ }^{18}$ 


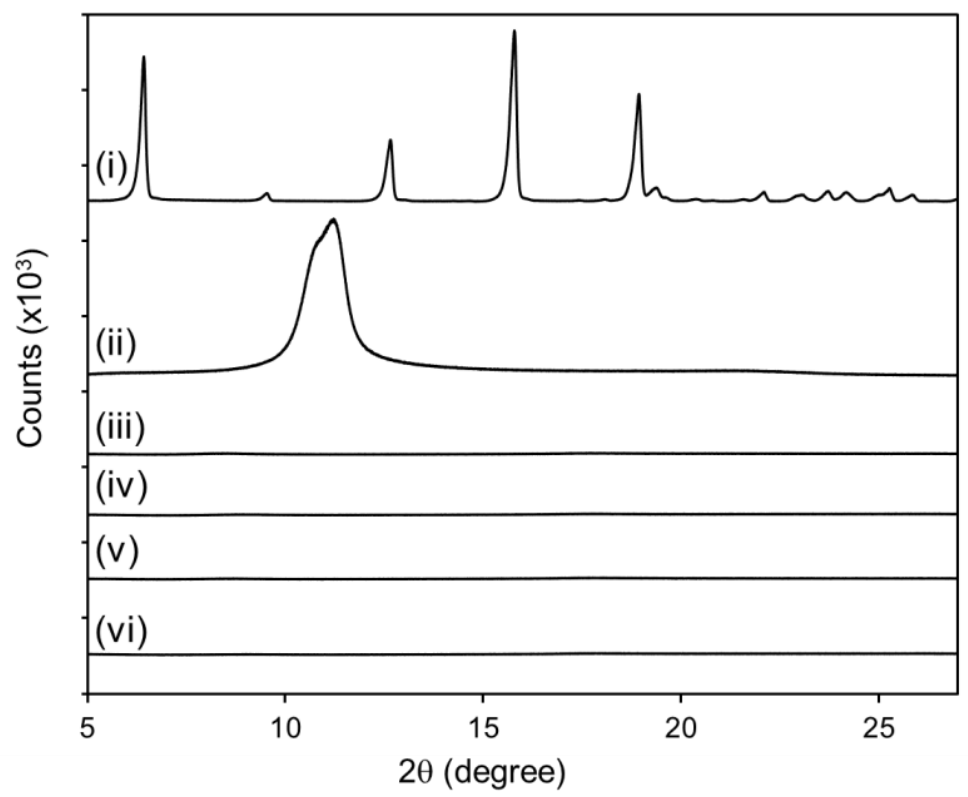

Figure 2. XRD patterns of (i) CPC, (ii) GO, (iii) GO-CPC, (iv) GO-CPC GO-CPCNH2.

Having elucidated the formation of the complexes between GO and CPCs, we next performed XPS analysis to confirm the elemental composition and the functional groups of GO-CPCs. The increase of carbon content was observed after the functionalization, suggesting the successful introduction of the long alkyl chain of CPCs. Notably, the chlorine content was much smaller than nitrogen, which could be attributed to the reaction of cationic pyridinium moiety with negatively-charged functional groups onto GO, thus removing chloride (Table S1). The XPS analysis at the N 1s region provided in-depth insights into the binding modes of the complexes (Figure 3). All GO-CPCs showed a peak of nitrogen around $401 \mathrm{eV}$, which corresponds to the pyridinium moiety of CPC. In contrast, GO-CPCNH2 showed another peak at $400 \mathrm{eV}$ derived from an amino group. When all $\mathbf{C P C}_{\mathbf{N H}} 2$ are attached covalently onto GO, via epoxide ring-opening, ${ }^{19}$ the ratio of ionic $\mathrm{N}(401 \mathrm{eV})$ and neutral $\mathrm{N}(400 \mathrm{eV})$ should be $1: 1$. However, the ratio of ionic $\mathrm{N}$ and neutral $\mathrm{N}$ was 5: 2 for GO-CPC $\mathbf{N H 2}$, suggesting ca. 30\% of $\mathrm{N}$ was covalently attached to GO, while the rest was interacting with the acidic functional groups of GO by 
ionic forces (Figure 3v). The $\mathbf{C P C}_{\mathbf{N H} 2}$ attached to $\mathrm{GO}$ via ionic interaction was removed by washing with $1 \mathrm{M} \mathrm{HCl}$, then neutralized with a base. The complex formed by this treatment was termed as GO$\mathbf{C P C}_{\text {NH2-wash. The ratio of ionic } \mathrm{N} \text { and neutral } \mathrm{N} \text { of GO-CPC }}$ NH2-wash became closer to 1:1 (Figure 3vi).
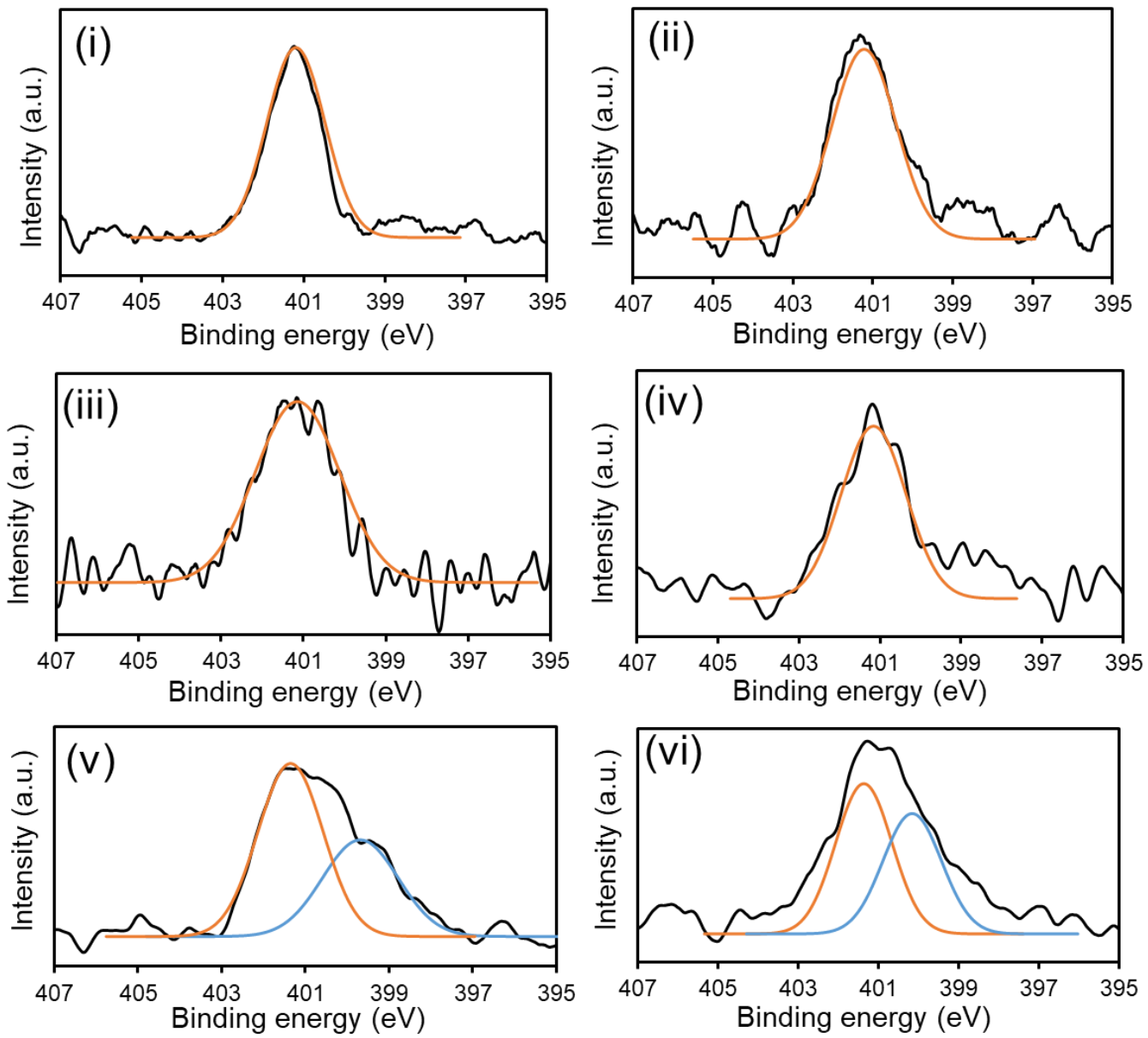

Figure 3. N 1s XPS analysis of (i) CPC, (ii) GO-CPC, (iii) GO-CPC CPC $_{\text {NH2, (vi) GO-CPC }}$ H2-wash. Orange: ionic C-N and blue: neutral C-N.

There is a previous paper on the interaction of GO with pyridinium species, in which GO and pyridinium are considered to interact through $\pi-\pi$ stacking. ${ }^{17}$ However, our ${ }^{1} \mathrm{H}$ NMR study (Figure S4), ${ }^{20}$ zeta potential analysis (Figure S5), and elemental analysis (especially, for Cl, Table S1) suggested the $\pi-\pi$ interaction is not a predominant binding force between GO and CPC. As proposed 
by Sampath et al. for the interaction of GO with various types of dyes, ${ }^{21}$ the interaction between GO and CPCs would be a synergy of $\pi-\pi$ interaction, van der Waals forces, ionic interaction, and hydrogen bonding.

\subsection{Antibacterial test and Release of CPCs from $G O$}

ATP assay is a high speed and simple method for the evaluation of antibacterial properties of a drug, ${ }^{22}$ thus used in hospitals to check the bacterial growth. ${ }^{23}$ Initially, we evaluated the antibacterial performance of GO and CPCs as controls. GO was proved to have limited antibacterial property. There have been arguments whether GO itself is antibacterial ${ }^{24}$ or not. $^{25,26}$ S mutans is one of the oral bacteria, which is tolerant even in acidic conditions. ${ }^{27} \mathrm{GO}$ did not show antibacterial performance toward $S$. mutans, while all CPCs and functionalized CPCs (CPC antibacterial activities (Figure 4).

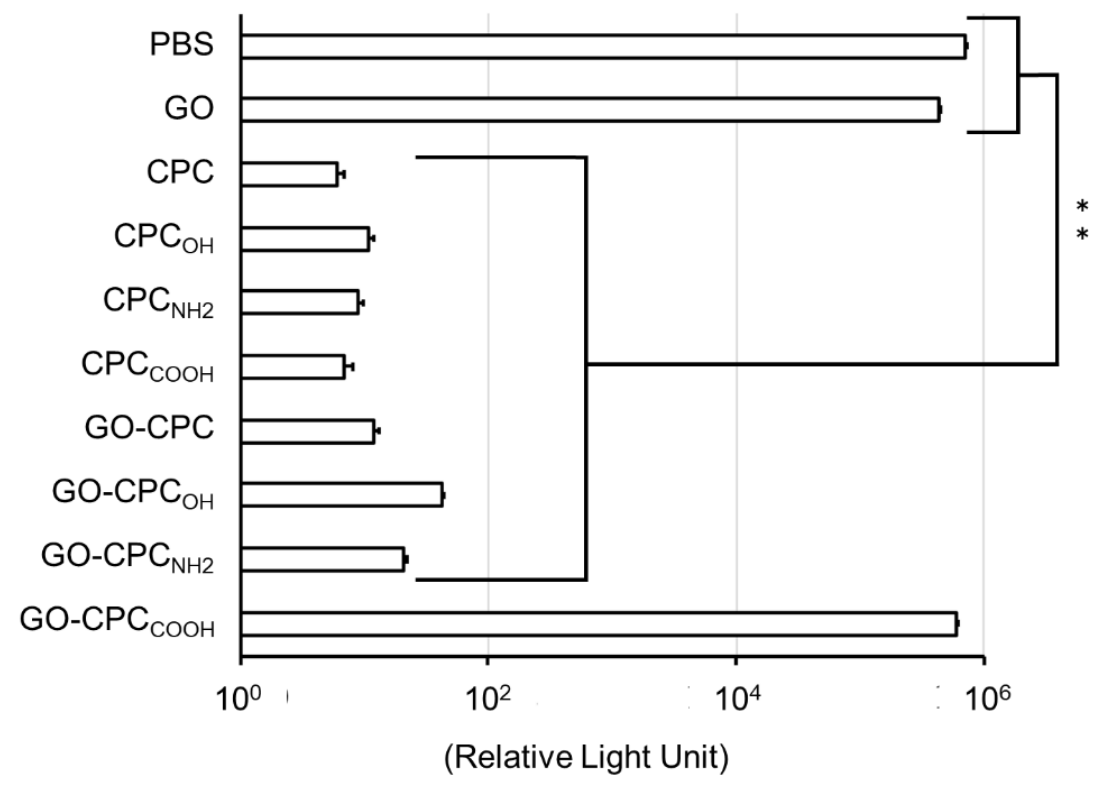

Figure 4. Antibacterial activity against cultured planktonic S. mutans. Data were obtained from the average values of the single experiment. The experiment was performed in triplicate $(\mathrm{N}=3)$, and measurements were performed three times per one specimen. $* *$ : $p<0.01$. 
Next, we analyzed the released compounds by ESI-MS. For GO-CPC $\mathbf{C O о H , ~ s m a l l e r ~ m o l e c u l a r ~ m a s s e s ~}$ than $\mathbf{C P C}$ Соoн were observed (Figure S6). Although the mechanism is unclear and requires more investigations, we consider that GO is likely able to oxidize ${ }^{28,29}$ the betaine-like CPCCooH moiety, resulting in the decomposition of the molecule. ${ }^{30}$ In contrast, CPCs were released from GO-CPC, GOCPCoH, and GO-CPC NH2 $_{2}$ while keeping their original molecular structures (Figure S7-S9). The decomposition of СРС Соoн on GO reflected the antibacterial performance; GO-CPCCOoH was not antibacterial, but the others, such as GO-CPC, GO-CPCoH, and GO-CPC $\mathbf{N H}_{\mathbf{N}}$, maintained the antibacterial performance of free CPCs (Figure 4).

The amount of released CPCs from GO-CPCs was then evaluated by measuring UV-Vis absorption at $260 \mathrm{~nm}$ of the GO-CPCs dispersions in water (Figure 5). Non-functionalized CPC was very little released from GO, while amino-functionalized $\mathbf{C P C}$ NH2 was the most susceptible to decomplex from $\mathrm{GO}$, suggesting ionic interaction between $\mathrm{GO}$ and $\mathbf{C P C}_{\mathbf{N H}}$ is predominant. Covalent bond formation to GO via epoxy ring-opening amination requires longer reaction time. ${ }^{19} \mathbf{C P C}$ oH showed an intermediate release profile between the other two conjugates. Under the current complexation conditions, we believe that the hydrophobic alkyl chain contributes mostly to the suppression of the release, and we recognized that tuning the released amount of CPCs was possible by changing a terminal functional group of the antibacterial agents. 


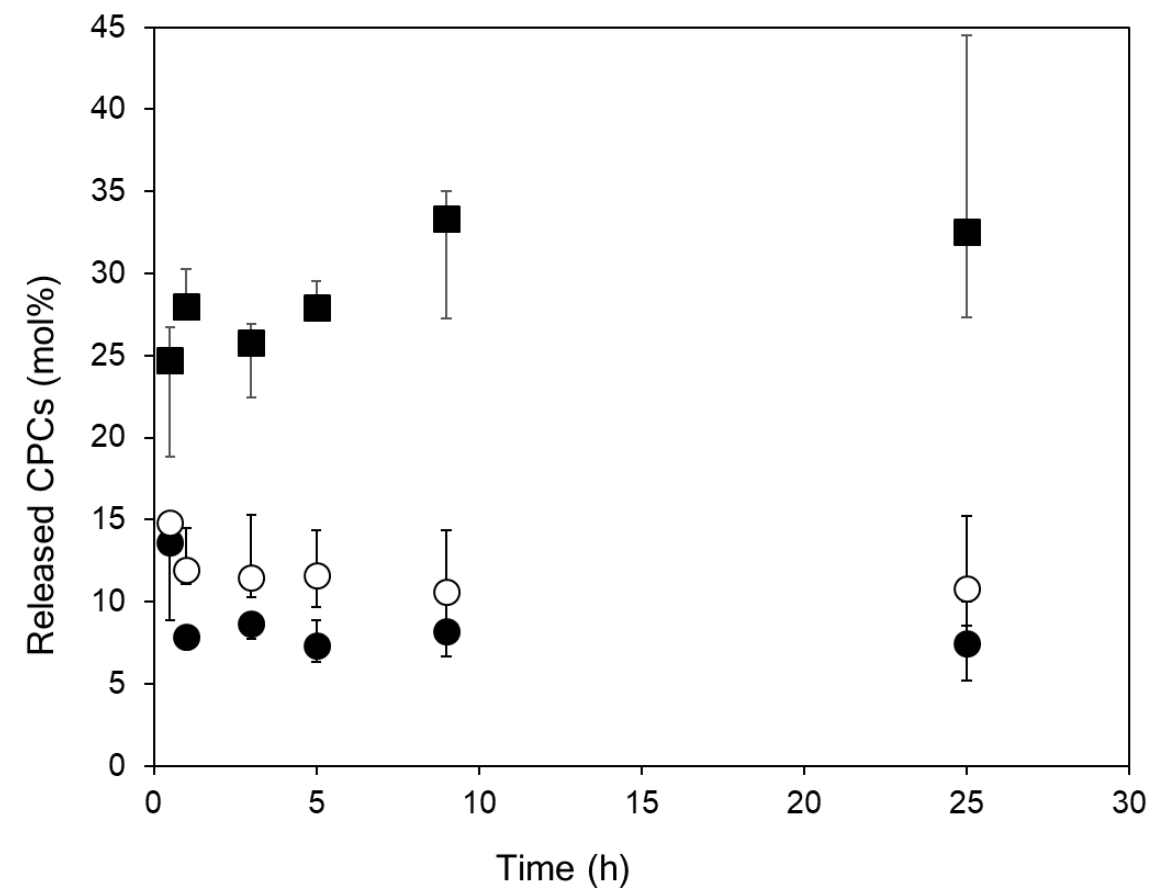

Figure 5. Time-course analysis of the released CPCs from $(\mathbf{O}) \mathbf{G O}-\mathbf{C P C},(\mathrm{O}) \mathbf{G O}-\mathbf{C P C}$, and ( $\mathbf{\square})$ GO-CPC ${ }_{\mathrm{NH} 2}$. Error bars indicate standard deviation $(\mathrm{N}=4)$.

\subsection{Mechanism of release of CPCs from $G O$}

Based on the above experiments, we propose a binding mode and release mechanism of CPCs complexed to GO. From the results of the elemental analysis by XPS after the functionalization, we found that chlorine, the counter anion of CPCs, was significantly reduced (Figure S10). This result suggests that oxygen functional groups and chloride ions on GO are substituted, and $\mathrm{HCl}$ is released (Figure 6a). When such an ion-exchange between GO and CPC occurs, the release of pyridinium generally does not take place. However, in practice, pyridinium species were detected by UV-Vis and ESI-MS measurements. We believe that this is because part of the oxygen functional groups eliminated by the reduction of GO worked as counter anions for pyridinium (Figure 6b). In fact, after refluxing GO-CPC for $1 \mathrm{~h}$ in water, it was confirmed that pyridinium release was three times higher than that 
of simple stirring, and that GO was reduced and strongly aggregated (Figure 6c and Figure S11). In the case of $\mathbf{C P C}_{\mathbf{N H} 2}$, the amino group strongly interact with the acidic functional groups on GO via ionic interactions, which could be reversible under physiological conditions (Figure S12A), resulting in larger amount of release than the other GO-CPCs.

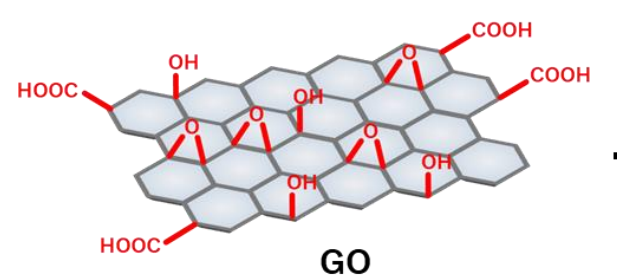

(c)

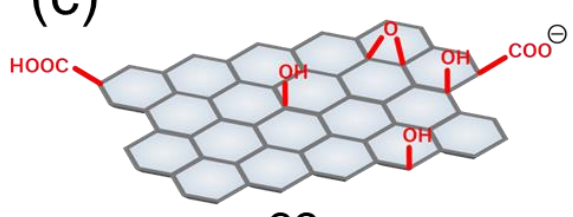

rGO

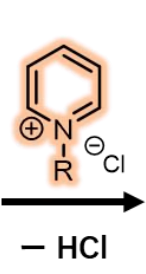

(a)
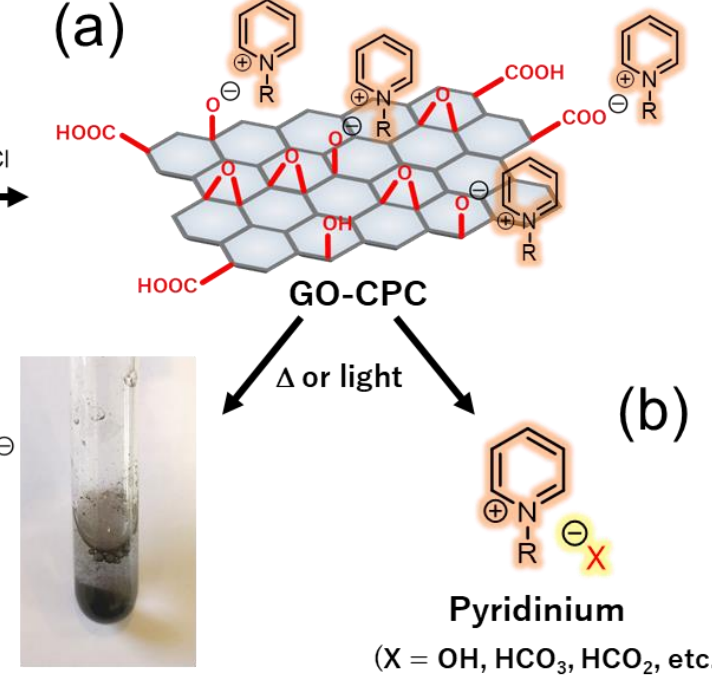

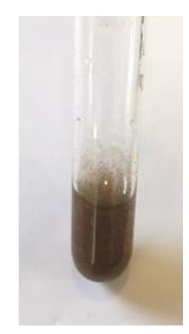

(b)

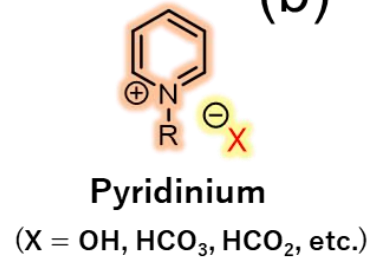

Figure 6. Proposed mechanism of the formation of GO-CPC and the release of pyridinium-containing molecules.

\section{Conclusion}

In this study, we focused on a well-known antibacterial molecule, namely $\mathrm{CPC}$, and verified the effect of its terminal functional group on the release from the GO surface. CPC without any functional group was very little released, and $\mathrm{CPC}$ with an amino group (CPC $\left.\mathbf{C H}_{\mathbf{N} 2}\right)$ was the most released. This suggests that GO-CPC is suitable for a sustained release of coated material, while GO-CPC $\mathbf{N H}_{\mathbf{N} 2}$ would be suitable as rapid-acting antibacterial materials, such as a drug. ${ }^{31}$ It was suggested that $\mathbf{C P C}$ COOH was degraded by the oxidizing character of GO, and antibacterial performance was not observed for GO- 
СРС соон. GO and CPCs were complexed by ion exchange, indicating that the release of pyridinium species is accompanied by the elimination of oxygen functional groups (reduction) of GO. The reduction of GO is known to proceed with heat and light. ${ }^{32}$ Therefore, we will consider releasing antibacterial molecules by such external stimuli in future studies.

\section{Acknowledgments}

We gratefully acknowledge the Centre National de la Recherche Scientifique (CNRS), the International Center for Frontier Research in Chemistry (icFRC), and financial support from the Agence Nationale de la Recherche (ANR) through the LabEx project Chemistry of Complex Systems (ANR-10-LABX-0026_CSC).

\section{References}

[1] S M. Simoes, L.C. Simoes, M.J. Vieira

A review of current and emergent biofilm control strategies LWT-Food Science and Technology 43(4) (2010) 573v583.

[2] G.K. Ramesha, A.V. Kumara, H.B. Muralidhara, S. Sampath

Graphene and graphene oxide as effective adsorbents toward anionic and cationic dyes

Journal of Colloid and Interface Science 361(1) (2011) 270-277.

[3] G.A. Carlson, J.L. Dragoo, B. Samimi, D.A. Bruckner, G.W. Bernard, M. Hedrick, et al. Bacteriostatic properties of biomatrices against common orthopaedic pathogens Biochemical and Biophysical Research Communications 321(2) (2004) 472-478.

[4] A.L. Hook, C.Y. Chang, J. Yang, J. Luckett, A. Cockayne, S. Atkinson, et al. Combinatorial discovery of polymers resistant to bacterial attachment Nature Biotechnology 30(9) (2012) 868-875.

[5] S.V. Pavlukhina, J.B. Kaplan, L. Xu, W. Chang, X.J. Yu, S. Madhyastha, et al. Noneluting Enzymatic Antibiofilm Coatings 
ACS Applied Materials \& Interfaces 4(9) (2012) 4708-4716.

[6] C. Desrousseaux, V. Sautou, S. Descamps, O. Traore

Modification of the surfaces of medical devices to prevent microbial adhesion and biofilm formation

Journal of Hospital Infection 85(2) (2013) 87-93.

[7] L. Shi, J. Chen, L. Teng, L. Wang, G. Zhu, S. Liu, et al.

The Antibacterial Applications of Graphene and Its Derivatives

Small 12(31) (2016) 4165-4184.

[8] D.R. Dreyer, S. Park, C.W. Bielawski, R.S. Ruoff

The chemistry of graphene oxide

Chemical Society Reviews 39(1) (2010) 228-240.

[9] V. Georgakilas, M. Otyepka, A.B. Bourlinos, V. Chandra, N. Kim, K.C. Kemp, et al.

Functionalization of Graphene: Covalent and Non-Covalent Approaches, Derivatives and Applications

Chemical Reviews 112(11) (2012) 6156-6214.

[10] R. Quisno, M.J. Foter

Cetyl Pyridinium Chloride

Journal of Bacteriol 52(1) (1946) 111-117.

[11] P. Gilbert, L.E. Moore, Cationic antiseptics: diversity of action under a common epithet, Journal of Applied Microbiology 99(4) (2005) 703-715.

[12] M. Okada, D. Hiramatsu, T. Okihara, T. Matsumoto

Adsorption and desorption behaviors of cetylpyridinium chloride on hydroxyapatite nanoparticles with different morphologies

Dental Materials Journal 35(4) (2016) 651-658.

[13] N. Morimoto, H. Suzuki, Y Takeuchi, S. Kawaguchi, M. Kunisu, C.W. Bielawski, et al.

Real-time, in situ monitoring of the oxidation of graphite: lessons learned

Chemistry of Materials 29 (5) (2017) 2150-2156.

[14] Y. Ito, T. Ito, K. Yamashiro, F. Mineshiba, K. Hirai, K. Omori, et al.

Antimicrobial and antibiofilm effects of abietic acid on cariogenic Streptococcus mutans

Odontology, 2019. https://doi.org/10.1007/s10266-019-00456-0.

[15] K. Krishnamoorthy, M. Veerapandian, K. Yun, S.J. Kim

The Chemical and structural analysis of graphene oxide with different degrees of oxidation

Carbon 53 (2013) 38-49.

[16] N. Morimoto, T. Kubo, Y. Nishina

Tailoring the Oxygen Content of Graphite and Reduced Graphene Oxide for Specific Applications 
Scientific Reports 6 (2016) 21715.

[17] X.L. Ye, X.M. Qin, X.R. Yan, J.K. Guo, L.H. Huang, et al.

$\pi-\pi$ conjugations improve the long-term antibacterial properties of graphene oxide/quaternary ammonium salt nanocomposites

Chemical Engineering Journal 304 (2016) 873-881.

[18] I.A. Vacchi, C. Spinato, J. Raya, A. Bianco, C. Menard-Moyon

Chemical reactivity of graphene oxide towards amines elucidated by solid-state NMR

Nanoscale 8(28) (2016) 13714-13721.

[19] W. Meng, E. Gall, F.Y. Ke, Z.H. Zeng, B. Kopchick, R. Timsina, et al

Structure and Interaction of Graphene Oxide-Cetyltrimethylammonium Bromide Complexation

Journal of Physical Chemistry C 119(36) (2015) 21135-21140.

[20] J.S. Zhang, J.S. Moore

Nanoarchitectures. 3. Aggregation of hexa(phenylacetylene) macrocycles in solution: a model system for studying .pi.-.pi. interactions

Journal of the American Chemical Society 114(24) (1992) 9701-9702.

[21] G.K. Ramesha, A.V. Kumara, H.B. Muralidhara, S. Sampath

Graphene and graphene oxide as effective adsorbents toward anionic and cationic dyes

Journal of Colloid and Interface Science 361(1) (2011) 270-277.

[22] N. Hattori, M. Nakajima, K. O’Hara, T. Sawai

Novel Antibiotic Susceptibility Tests by the ATP-Bioluminescence Method Using Filamentous Cell Treatment

Antimicrobial Agents and Chemotherapy 42 (6) (1998) 1406-1411.

[23] J.M. Boyce, N.L. Havill, D.G. Dumigan, M. Golebiewski, O. Balogun, R. Rizvani

Monitoring the effectiveness of hospital cleaning practices by use of an adenosine triphosphate bioluminescence assay

Infection Control and Hospital Epidemiology 30(7) (2009) 678-684.

[24] S.F. Kiew, L.V. Kiew, H.B. Lee, T. Imae, L.Y. Chung

Assessing biocompatibility of graphene oxide-based nanocarriers: A review

Journal of Controlled Release 226 (2016) 217-228.

[25] L. Liu, J. Liu, Y. Wang, X. Yan, D. D. Sun

Facile synthesis of monodispersed silver nanoparticles on graphene oxide sheets with enhanced antibacterial activity

New Journal of Chemistry 35 (2011) 1418-1423.

[26] S. Bengtson, K. Kling, A.M. Madsen, A.W. Noergaard, N.R. Jacobsen, P.A. Clausen, et al.

No cytotoxicity or genotoxicity of graphene and graphene oxide in murine lung epithelial FE1 cells in vitro

Environmental and Molecular Mutagenesis 57(6) (2016) 469-482. 
[27] R. Matsui, D. Cvitkovitch

Acid tolerance mechanisms utilized by Streptococcus mutans

Future Microbiology 5(3) (2010) 403-417.

[28] K. Morioku, N. Morimoto, Y. Takeuchi, Y. Nishina

Concurrent formation of carbon-carbon bonds and functionalized graphene by oxidative carbon-hydrogen coupling reaction

Scientific Reports 6 (2016) 25824.

[29] D.R. Dreyer, H.P. Jia, C.W. Bielawski

Graphene oxide: a convenient carbocatalyst for facilitating oxidation and hydration reactions

Angewandte Chemie International Edition 49(38) (2010) 6813-6816.

[30] J. Heijthuijsen, T.A. Hansen

Betaine fermentation and oxidation by marine desulfuromonas strains

Applied and Environmental Microbiology 55(4) (1989) 965-969.

[31] C. McCallion, J. Burthem, K. Rees-Unwin, A. Golovanov, A. Pluen

Graphene in therapeutics delivery: Problems, solutions and future opportunities,

European Journal of Pharmaceutics and Biopharmaceutics 104 (2016) 235-250.

[32] M. Hada, K. Miyata, S. Ohmura, Y. Arashida, K. Ichiyanagi, I. Katayama, et al.

Selective Reduction Mechanism of Graphene Oxide Driven by the Photon Mode versus the Thermal Mode

ACS Nano 13(9) (2019) 10103-10112. 